\title{
Thermal conductivity of clay based material incorporating Argan Shell: Experimental characterization
}

\author{
Aicha Idoum $^{1 *}$, Lahcen Bammou ${ }^{1}$, Rachid Tiskatine ${ }^{1}$, and Ahmed Aharoune ${ }^{1}$ \\ ${ }^{1}$ Thermodynamics and Energetics Laboratory, Faculty of Science, IbnZohr University, BP8106, 80006 Agadir, Morocco
}

\begin{abstract}
This research investigated the impact of agricultural biomass additives (Argan shell) on the thermal and physical properties of fired clay bricks for building application. The objective of the study is to characterize the selected materials from molecule up to the final materials used in buildings. The materials used in this study, are soil and Argan shells, locally available materials for brick making. The Argan shells were grinded and then added to the clay mixture. The Clay brick shows a formation of pores during the firing process up to $1050^{\circ} \mathrm{C}$. As results, the bulk density of the clay bricks decreased due to the pores formation. On the other hand, the thermal conductivity of the clay bricks was reduced by $53 \%$ using $20 \mathrm{wt} \%$ of the biomass additives.
\end{abstract}

\section{Introduction}

The building sector consumes a significant part of the energy, therefore it is a source of a significant part of the pollution. To reduce the associated greenhouse gas emissions, it was necessary to use environmentally sustainable building materials [1]. To this purpose the fired clay bricks industry is making efforts to invent new materials based on clay and additives that are locally available, natural, recyclable and environmentally friendly. These qualities make clay and naturel additives the new building materials of the future.

Today, one third of the world's population still lives in mud housing[2]. However, agricultural biomass additives such as straw improve the properties of mud bricks[1].Consequently, studying these properties is a first step in evaluating the impact of the material not only on energy consumption, but also on indoor comfort[3].

The use of organic additives has increased worldwide, mainly due to their availability and also for their thermal, mechanical and environmental impact[410].As a result, the incorporation of biomass additives into clay bricks can reduce thermal conductivity and enhance compressive strengths.

In our case, we used the argan shells as additives to the clay blocks; Argan trees are located mainly in the sous massa region. The forest of argan occupies an area of 830,000 ha[11]. Argan nuts are used to extract argan oil and generally the shells are used as fuel and that builds up greenhouse gases. The annual quantity of discards in Morocco is approximately 60 thousands of tons[12].Then the incorporation of argan shells in clay blocks especially for local use is the best solution for the recycling of this material without affecting the environment.

The aim of this paper is to study the behavior of the fired clay blocks incorporation argan shells as additives then to characterize their thermal and physical properties.

\section{Materials and methods}

\subsection{Materials}

The materials used in this study, are soil and argan shells, which both come from the Souss Massa region.

\subsubsection{Clay}

The clay was extracted from a quarry (red clay) (fig.1). According to the geotechnical analysis, the clay sample is identified as sandy clay.

The identification tests that we carried out on the soil sample are the particle size analysis by sieving (NF P94056), the particle size analysis by sedimentation (NF P94-057), The liquidity limit (WL) by the cone method (NF P-94-052-1), The plastic limit (NF P 94-051) and the methylene blue test (NF-P94 068).

For the mineralogical characterization of the clay sample we used an X-ray diffraction (XRD) a BRUKER D8 Advance Eco.

\footnotetext{
* Corresponding author: aicha.idoum@edu.uiz.ac.ma
} 


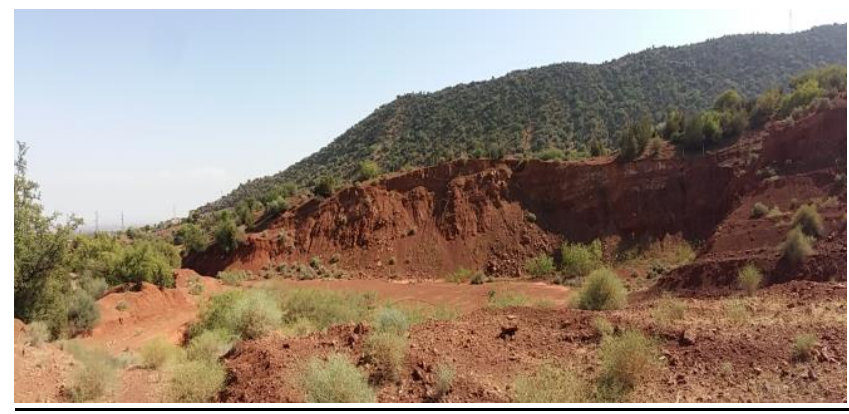

Fig. 1. The panoramic view of the red clay quarry

\subsubsection{Argan shells}

The Argan shells waste were collected from argan products cooperatives at Souss Massa Morocco after the extraction of nuts. Argan shell represented about $86 \%$ of the argan fruit weight and is mainly composed of $25 \%$ Cellulose, $34.3 \%$ Hemicelluloses and $34.5 \%$ Lignin[12]. The powder used of the argan shell (A) (Fig.2) is obtained by grinding the shells of argan using a knife mill. The powder used is sieved between 1 and $0.5 \mathrm{~mm}$ diameter sieves.

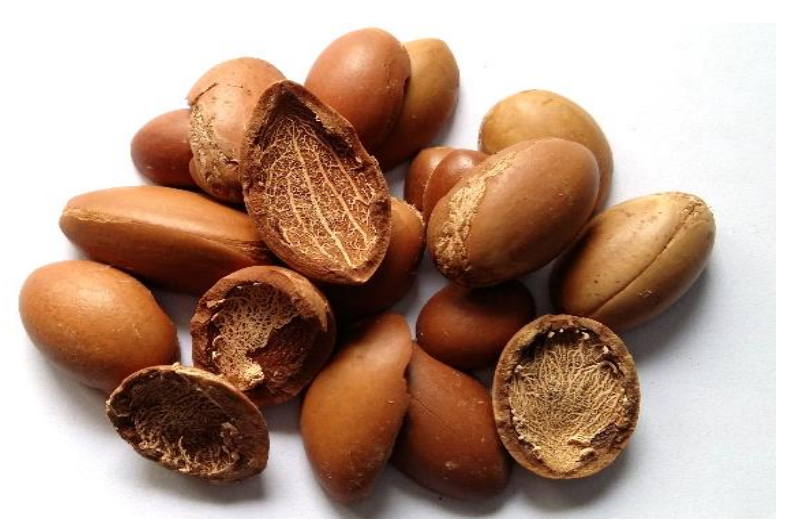

Fig. 2. The Argan shells

\subsection{Brick manufacturing method:}

We have made the bricks samples by varying the percentages of additive and red clay (Table1).Samples with $0 \%$ biomass additive were made to compare the impact of the biomass additives incorporated in the bricks.

The samples were mixed until homogeneity with the minimal amount of water to get the right plastic consistency, then molded and compacted into a 160x40x40 mm3 parallelepiped wood mold. To prevent the mixture from sticking to the sides of the mould we previosly covered the sides with clay this method prevents bricks from deformation .

The samples are dried at room temperature 48 hours, then at $105^{\circ} \mathrm{C}$ for 24 hours until constant mass is reached. The bricks were baked in an electric oven up to $1050^{\circ} \mathrm{C}$.

The samples are cooled to room temperature inside the oven by natural convection. The fired brick samples were designated RA0, RA5, RA10, RA15, and RA20 (Fig.3).
The Bulk density and the porosity percentage of the samples are measured.

Table 1. The samples composition.

\begin{tabular}{|c|c|c|}
\hline & Clay (R)\% & $\begin{array}{c}\text { Argan shells } \\
\text { (A) \% }\end{array}$ \\
\hline RA0 & 100 & 0 \\
\hline RA5 & 95 & 5 \\
\hline RA10 & 90 & 10 \\
\hline RA15 & 85 & 15 \\
\hline RA20 & 80 & 20 \\
\hline
\end{tabular}

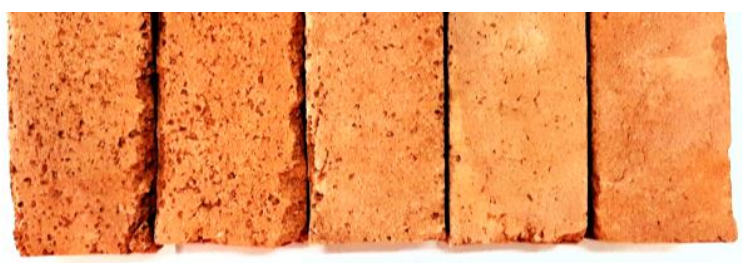

Fig. 3. Enlarged image of the samples RA20, RA15, RA10, RA5, and RA0 from left to right

\subsection{Thermal Conductivity measurement:}

The thermal conductivity was determined using a Hot Disk TPS1500 system .The measurement principle consists in imposing a uniform heat flux on the sample surface by a probe (sensor) consisting of a double nickel spiral with $10 \mu \mathrm{m}$ in thickness and sandwiched between two sheets of Kapton insulator. The Hot Disk sensor used as both heat source and dynamic temperature sensor. The increase in its electrical resistance corresponds to the temperature increase of the sample surface facing the sensor ( $\Delta \mathrm{t}$ ave).

The Hot Disk is electrically heated causing the increase in temperature which is directly related to the variation in the sensor resistance $\mathrm{R}(\mathrm{t})$ by the equation [5]:

$$
R(t)=R 0[1+r(T i+\text { Tave })]
$$

Where

$\mathrm{R} 0$ is the resistance of the disk just before heating (at time $\mathrm{t}=0$ ),

$r$ is the temperature coefficient of the resistivity $\Delta \mathrm{Ti}$ is the constant temperature difference that develops almost momentarily over the thin insulating layers covering the two sides of the sensor $(\Delta \mathrm{ti}=0$ when the thermal contact is perfect). 


\section{Results and discussion}

The clay sample is identified as sandy clay, according to the analysis (Table2).

Table 2. Clay sample properties.

\begin{tabular}{|c|c|}
\hline $\mathrm{pH}$ & 9.03 \\
\hline $\begin{array}{c}\text { Liquid limit } \\
\text { (LL) }\end{array}$ & 19 \\
\hline $\begin{array}{c}\text { Plastic limit } \\
\text { (PL) }\end{array}$ & 13 \\
\hline $\begin{array}{c}\text { Plasticity } \\
\text { Index (PI) }\end{array}$ & 6 \\
\hline
\end{tabular}

The particle size distribution of the clay sample is shown in Fig. $4,12 \mathrm{wt} . \%$ is presented by clay $(<2 \mu \mathrm{m}), 35 \mathrm{wt} . \%$ by silt, and $53 \mathrm{wt} . \%$ by sand $(>63 \mathrm{~mm})$.

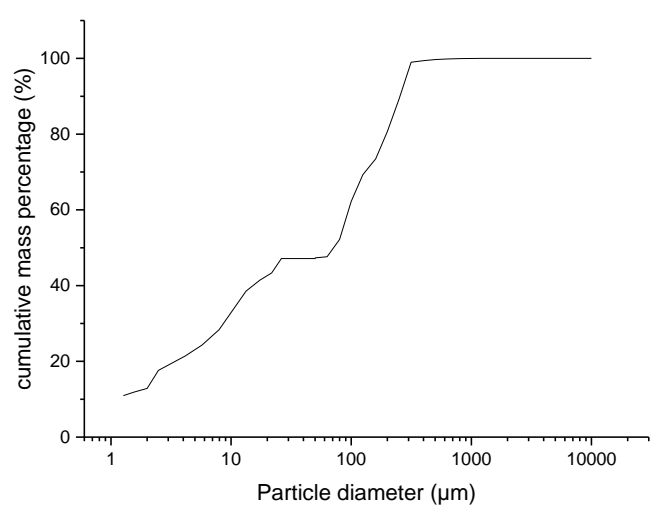

Fig. 4. The particle size distribution of the clay sample

This result is consistent with the X-ray diffraction data (Fig. 5), quartz, illite, kaolinite, and calcite are The main crystalline phases of the sample.

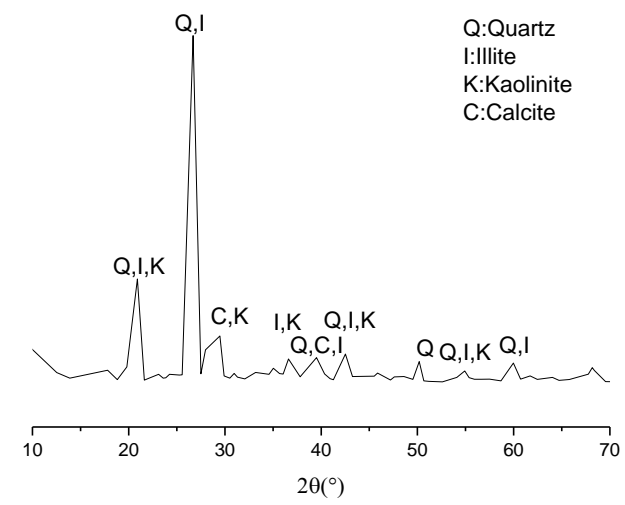

Fig. 5. X-ray diffraction pattern of the clay sample

The physical properties of the smples composite show that incorporating biomass additives in fired clay bricks reduces the bulk density to $42 \%$ and increases the porosity by $32 \%$ using $20 \mathrm{wt} \%$ of argan shell additive (Fig.6).

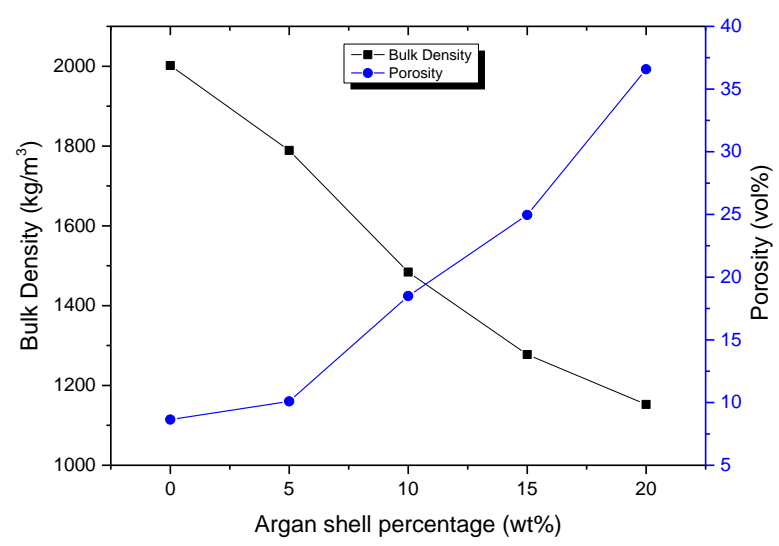

Fig. 6. Dependence of the bulk density and porosity percentage of the clay bricks on the percentage of argan shell additives after firing at $1050{ }^{\circ} \mathrm{C}$.

The thermal conductivity of the bricks is presented in Fig.7. The results show that the bricks with argan shell additive reach a conductivity of $0.27 \mathrm{~W} / \mathrm{mK}$.

The thermal conductivity is reduced by $53 \%$ using $20 \mathrm{wt} \%$ of argan shell additive.

The decrease of the thermal conductivity is associated to the formation of pores, $36 \%$ for RA20 sample.

In fact, the thermal conductivity decreases because of the low thermal conductivity of air in the newly formed pores[4].

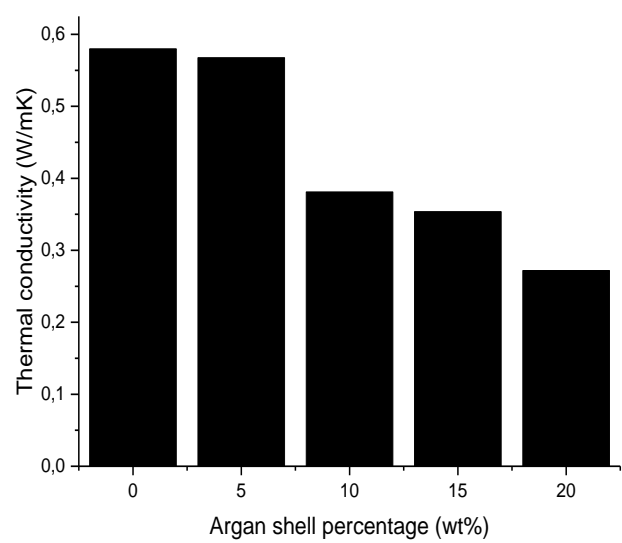

Fig. 7. Dependence of the thermal conductivity of the clay bricks on the percentage of argan shell additives after firing at $1050{ }^{\circ} \mathrm{C}$

\section{Conclusion}

Argan shells used as additives to the clay bricks matrix to create a new biocomposite, naturel, recyclable and environmentally friendly materials for building applications.

The aim of this study is to use locally available materials as building materials in order to improve the energy efficiency of buildings by reducing thermal conductivity and improving physical properties such as bulk density. 
To analyze the impact of the percentage of biomass additives on the properties of bricks, we added 5, 10, 15 and $20 \mathrm{wt} \%$ with a particle size diameter $0.5 \mathrm{~mm} \leq \varnothing$ $\leq 1 \mathrm{~mm}$ to the mixture of red clay.

The clay samples show that the thermal conductivity decreased with the increase in the percentage of additives and this is due mainly to the formation of air pores in the bricks.

\section{References}

1. F. Pittau, F. Krause, G. Lumia, and G. Habert, "Fast-growing bio-based materials as an opportunity for storing carbon in exterior walls," Build. Environ., vol. 129, no. December 2017, pp. 117-129, 2018.

2. G. Guest, R. M. Bright, F. Cherubini, and A. H. Strømman, "Consistent quantification of climate impacts due to biogenic carbon storage across a range of bio-product systems," Environ. Impact Assess. Rev., vol. 43, pp. 21-30, 2013.

3. M. Labat et al., "From the experimental characterization of the hygrothermal properties of straw-clay mixtures to the numerical assessment of their buffering potential To cite this version : HAL Id : hal-01785406 properties of straw-clay mixtures to the numerical," 2018.

4. P. Nigay, A. Nzihou, and T. Cutard, "The Impact of the Particle Size Distribution of Organic Additives on the Microstructure of a Clay Ceramic and Its Thermal and Mechanical Properties," vol. 30, no. 4, pp. 2-9, 2018.

5. R. Tiskatine et al., "Thermo-physical analysis of low-cost ecological composites for building construction,” J. Build. Eng., vol. 20, no. September, pp. 762-775, 2018.

6. J. A. Lozano-miralles and M. Jes, "Comparative Study on the Environmental Impact of Traditional Clay Bricks Mixed with Organic Waste Using Life Cycle Analysis," 2018.

7. H. Essabir et al., "Materia ls and Design Mechanical and thermal properties of biocomposites based on polypropylene reinforced with Nut-shells of Argan particles," vol. 49, pp. 442-448, 2013.

8. L. Barbieri, F. Andreola, I. Lancellotti, and R. Taurino, "Management of agricultural biomass wastes : Preliminary study on characterization and valorisation in clay matrix bricks," vol. 33, pp. 2307-2315, 2013.

9. A. N. Adazabra, G. Viruthagiri, and N. Shanmugam, "Management of spent shea waste : An instrumental characterization and valorization in clay bricks construction," Waste Manag., vol. 64, pp. 286-304, 2017.

10. G. Görhan and S. Osman, "Porous clay bricks manufactured with rice husks," vol. 40, pp. 390 396, 2013.
11. H. Essabir, M. O. Bensalah, D. Rodrigue, R. Bouhfid, and A. E. K. Qaiss, "Biocomposites based on Argan nut shell and a polymer matrix: Effect of filler content and coupling agent," Carbohydr. Polym., vol. 143, pp. 70-83, 2016.

12. M. Tatane, H. Elminor, M. Ayeb, and A. Lacherai, "Effect of Argan Nut Shell Powder on Thermal and Mechanical Behavior of Effect of Argan Nut Shell Powder on Thermal and Mechanical Behavior of Compressed Earth Blocks," no. April, 2018. 